\title{
Using Visuals to Promote On-Task Behavior and Independence for Students with Autism Spectrum Disorder
}

\author{
Kate D. Simmons \\ Auburn University Montgomery \\ 7430 East Dr, Montgomery, AL 36117, United States \\ Vanessa Hinton \\ Auburn University \\ Auburn, AL 36849, United States \\ Amelia Padgett \\ Auburn University Montgomery \\ 7430 East Dr, Montgomery, AL 36117, United States
}

\begin{abstract}
Strategies that address the needs of children with Autism Spectrum Disorder (ASD) across all educational setting are an essential component for improving independence and promoting the success of students with ASD. This paper assesses the impact of visual assistance through the use of an individual work system and a visual communication system such as the picture exchange communication system (PECS) in a special needs classroom setting. The purpose of this intervention was to decrease the off-task behavior while also supporting the independence of a single student in a resource classroom. Baseline data were taken for four consecutive days. Intervention data were then taken for two weeks. Data consisted of the student's off-task behavior and adult prompting. Data indicate that the visual support not only decreased the student's off-task behavior, but the need for adult prompting as well.
\end{abstract}

Keywords: ASD, individual work system, picture exchange communication system, off-task behavior, adult prompting

\section{Prevalence and Characteristics of ASD}

The National Information Center for Children and Youth with Disabilities (NICHCY; 2004) states that autism is a developmental disorder that causes impairment in the way an individual processes information (Rao \& Gagie, 2006). This disorder is life-long. Students with autism spectrum disorder (ASD) generally have difficulties with communicate, understand language, play, develop social skills, and relate to others (Rao \& Gagie, 2006). Students with ASD have a dependence on adults for staying on-task, completing activities, and transitioning between activities (Koegel \& Koegel, 1995). In addition, many individuals with autism do no automatically discriminate cues in their environment that are needed to function independently (Hodgdon, 1995). Teaching students with ASD in an educational setting is an increasingly difficult challenge for school administration and personnel. In the public school setting, the number of students served is increasing dramatically. The U.S. Department of Education Data Accountability Center reported in 2006 there had been a 4.000\% increase of children diagnosed with autism spectrum disorder from 1991- 2006.

Due to the dramatic increase in numbers of students' diagnosed with ASD, there has been an overwhelming amount of effort invested in gaining information about how to better accommodate students with autism (Hume, Plavnick, \& Odom, 2012). Meeting the varied needs of students with autism is the school setting is a crucial element for expediting the success of these complex students. Research shows that a considerable amount of individuals diagnosed with ASD have difficulty attending to multiple stimuli and environmental cues. (Quill, 2000). Therefore, individuals with autism attend to parts rather than wholes and have a tendency to focus on one object unaware of their surroundings. Because of these deficits, students with ASD are generally limited in their comprehension and understanding. These individuals often do not comprehend the "big picture" (Happe \& Frith, 2006). Due to poor communication, processing, and focusing skills students with ASD often are unable to identify the task at hand, determine where to begin, or how to achieve the task. Completing an activity from start to finish is challenge. These tasks make it difficult for a student to be independent (Fisher \& Happe, 2005).

\section{Supporting Students with ASD}

Because of these barriers there is a great demand for additional support for students with ASD in the classroom. School staff such as special education teachers and paraprofessionals are an important part of the development, implementation, and monitoring of student success in the classroom (Brock, Jimerson, \& Hansen, 2006, p. 88). Early 
intervention is an essential component of children diagnosed with autism. (National Research Council, 2001). Some of the leading characteristics include appropriate services, objectives, and interventions for students with ASD to be successful. These broad areas can be categorized as: communication, cognitive development, social skills, and play skills (Iovannone, Dunlap, Huber, \& Kincaid, 2003).

Most children with ASD are visual learners. Using supports formed on accurate and visual assistance has been a popular form of intervention. Supports are used in a variety of settings. The settings include school, home, work, and community (Kluth and Darmondy-Latham, 2003).

Visual supports provide the student with a better understanding of expectations.

They assist with structure and routine throughout day which many students with autism

need to be successful in a classroom. There are numerous reasons to incorporate visual supports into an autistic students' schedule. First, visual supports are part of everyone's communication system. Second, visual aids are colorful and attractive so it holds a student's attention. The third reason visual supports are helpful is that they enable the student to focus on the message and reduce uncertainty. Fourth, visual support makes complex concepts more real for the student. Finally, visual supports help the student express his or her thoughts, wants, and needs.

A visual schedule or scripted routine as an intervention strives to promote independence for students with ASD. A picture schedule will show a student when events are going to happen throughout the day (Rao \& Gagie, 2006). Visual information is accessed when the student needs it. Visual aids decrease the use of verbal prompts by the teacher or caregiver. Visual prompts mean that a student can perform the task without having to have a verbal command during every step of the activity. There are many types of visual cues such as: visual calendars, visual schedules, now and then cards, visual scripts, and cue cards.

\section{Individual Work Systems}

An individual work system is an organizational system that teaches students using visual supports. This instructional strategy aims to increase independence in students with autism and decrease adult support. A work system is a visual to show a student the task when arriving at a work station. Work systems are an attempt to provide students with ASD a meaningful and organized approach to help them begin and finish a number of tasks or activities independently (Mesibov, Shea, \& Schopler, 2005). An individual work system is designed to answer four questions:

- What is the activity to be completed?

- How much work or how many tasks are required?

- When is the task complete?

- What happens after this activity is over? (Mesibov et al., 2005).

Visual organization and work systems meet the needs of students with ASD in similar ways: they highlight important information and limit distractions, offer a clear and routine sequence of activities, minimize the need for verbal instructions, practice acquired skills, and minimize the need for adult prompting (Hume, K., \& Reynolds, B., 2010).

\section{Picture Exchange Communication System (PECS)}

Some individuals with autism are verbal while others may never speak. The Picture Exchange Communication System (PECS) is a communication system developed to assist autistic students with communication. This system was designed to assist individuals quickly achieve a useful way to interact with others (Bondy \& Frost, 1994). PECS is a beneficial way to implement language and a way to communicate for those individuals who are non-verbal and implement a schedule to assist with daily tasks. PECS teaches children to initiate their desires by exchanging pictures for something they want or need, make the transition easier, and assists with predictability (Hume \& Odom, 2007).

\section{Method}

\section{Participant}

One 10 year old male student with ASD participated in this study. For confidentiality, his name has been changed to Derek. Derek received his diagnosis in 2006. Upon arriving at his current school in the fall of 2013, he was observed and evaluated by the local school personnel and was determined eligible for placement in the resourcebased classroom. The student spends the majority of his day in the resource room. When in the general education setting, he is supported by a paraprofessional.

Derek was chosen to participate in this single-subject research because of his poor communication skills, off task behavior, and his dependence for adult assistance. In a parent interview, his mother stated that her son had little experience with any visual learning techniques prior to this study.

The parent and teacher both reported that the student was verbal but did not communicate his wants or needs. He often babbles to himself, used echoic speech, and does not answer questions such as who, what, when, and where.

Transition time and independent work time are very difficult times for the student. The student often became very anxious and frustrated throughout the day when told to go from one activity to another and during independent work time. During transition time the student often demonstrated self-stimulating behavior such as rocking, flapping his 
hands, stomping his feet, and locking his knees refusing to go to the next assigned task. During independent work time the student would bite his fingers, recite 1-800 numbers, and hit himself on top of his head.

\section{Setting, Material, and Equipment}

The special education teacher and one paraprofessional serve eight students in the resource room. The classroom is arranged in different sections that are clearly identifiable through furniture arrangement and visual markings. Individual desks were located in the center of the room. A small group area was located in the front corner of the room. Student work stations, the computer center, the table task area, and free play areas were around the perimeter of the room. Each area was sectioned off with partitions. The student's Picture Exchange Communication System (PECS) schedule was located alongside a filing cabinet in a central location in the classroom. The materials the student completed during the individual work system consisted of file folder games and activities. The games were copied from Carson-Dellosa’s File Folder Games (Carson \& Dellosa, 1990). The games were glued onto manila file folders.

\section{Intervention}

The PECS was located in the special education resource classroom. This intervention was implemented in a 1:1 context, throughout the school day, 5 days a week. The PECS was enforced to teach the student to use the picture cards as a schedule. The schedule consisted of 14, $3 \times 3$ inch plastic picture cards on a vertical strip of velcro. The picture cards indicated what task the student was to perform every thirty minutes. For each task the student had to walk to his schedule board, take the picture card, go to the assigned area, place the picture cards on the velcro strip, and complete the activity. Once the activity was complete, the student was to take the picture card off the velcro board and place it in the done/completed box located on the filing cabinet beside the schedule. Next, the student had to look at his schedule board, take the next card, and begin the next task. Looking at a picture schedule indicated to the student the next activity to begin. Although this student did not communicate verbally, he could read aloud. To begin the intervention the teacher had the student read aloud his daily schedule. For example, the student read, "8:00sensory time, 8:30- language group.” After the student orally read his schedule to the teacher, the student and teacher matched the picture cards to the written words on his schedule. It was important for the student to make sense of the new schedule. The schedule was carefully organized according to activities that were preferred by the student and interchanged with tasks that the student did not enjoy or that were more difficult. For two weeks the teacher trained the student to use the new picture schedule. During the first five days the teacher walked the student through the PECS schedule throughout the entire school day. The teacher gave prompts including verbal cues; hand over hand demonstrations to show the student how to implement the PECS into his daily schedule. The student was told to "check in" when beginning an activity and to "check out" when the activity was complete. Checking in and out at the visual schedule board indicated to the student that he was finished with the activity and to place his picture card in the done/completed box. Gradually the teacher began fading the prompts on days four and five of training. By the end of the two week intervention, the student only needed verbal cues occasionally to be reminded to "check-in" or "check-out".

The independent work system was implemented in the special education resource classroom. The intervention took place during the students independent work time in the morning for 30 minutes daily. Independent work time consisted of practicing tasks that the student had mastered. The basic left-to-right work system was deemed appropriate for the student by the resource room teacher. The independent work system was taught to the student by a combination of hand-over-hand assistance, visual prompts, and two or three word verbal cues. After four days of hand-over-hand assistance, the teacher began non-verbal prompting and stood behind the student as a means to fade out the prompts all together and to give the student more independence. The individual tasks the student had to complete were to the left of the student and to the right was an empty basket for completed work. Because the student had mastered matching, the student was shown how to match a sequence of visual symbols to the one on the task drawers. When all symbols were matched and the drawers were empty the student understood that this indicated the task was complete. Through the work system, the student visually learned four things. The student learned what task was expected of him, how much work was expected, when he was finished, and what would happen next. In this case, the next activity was snack time which was a big motivator for the student to stay on task and complete the tasks.

\section{Data}

Data were collected on the student's off-task behavior during independent work station time and on the level of adult prompting required for the student to successfully complete his work independently. The data were graphed so the teacher could make an informed decision regarding the success of the visual assistance of the work system and the visual communication system in the special needs resource classroom. The student was considered on task when he was on schedule, used the picture activity schedule, "checked in and out" at the schedule board, manipulated any activity/work appropriately, and transitioned from one task to another independently. Off-task behavior was defined as a student not being on schedule, engaging in self-stimulating behavior such as bouncing, hitting his own head, biting his fingers, displaying inappropriate behaviors such as refusal to work and throwing tantrums. Adult prompting 
was defined throughout the observation as verbal cues, pointing to work, hand-over-hand prompting, and a gentle tap on the shoulder.

Baseline data were first collected on the student's off-task behavior. Data indicated that the student was off task 8.5 times during a 30 minute independent work system. Baseline data were then collected on the students need for adult prompting during a 30 minute transition time from the time he "checked in" on his daily schedule for one activity until he "checked-out" on his PECS schedule board. Data indicated that the student needed adult prompting an average of 7 times during an activity and/or work time. Intervention data taken on the students' off-task behavior during an independent work system over a two week time frame showed that the students' off-task behavior decreased. The average number of times the student was off-task during the two week intervention was 4.3 times.

Figure 1: Adult prompts directing student to stay on task.

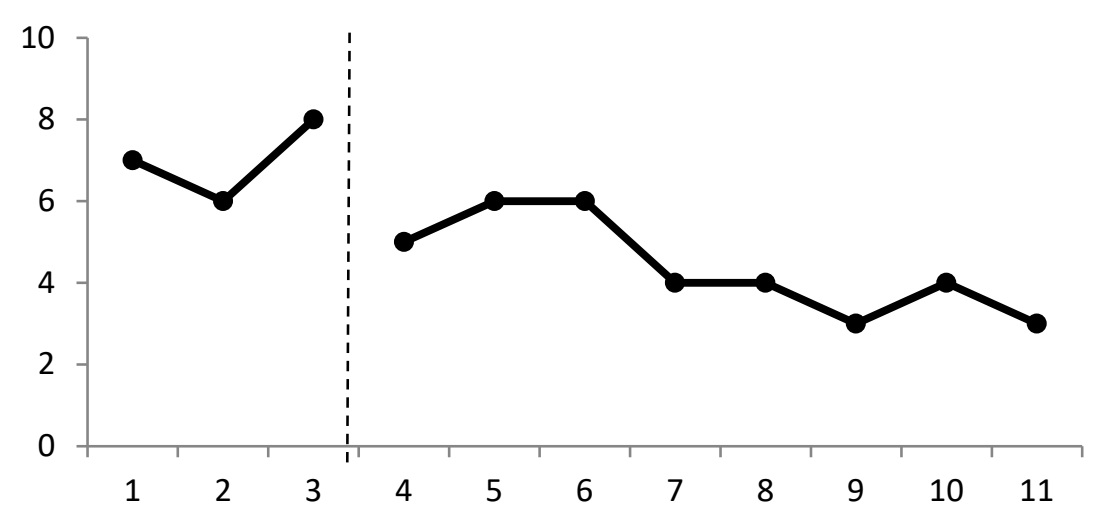

Intervention data on the students' need for adult prompting during the two-week intervention also decreased to an average of 4.4 times in a $30-\mathrm{min}$. time frame.

Figure 2: Off task behaviors in the special education classroom setting during a thirty minute period.

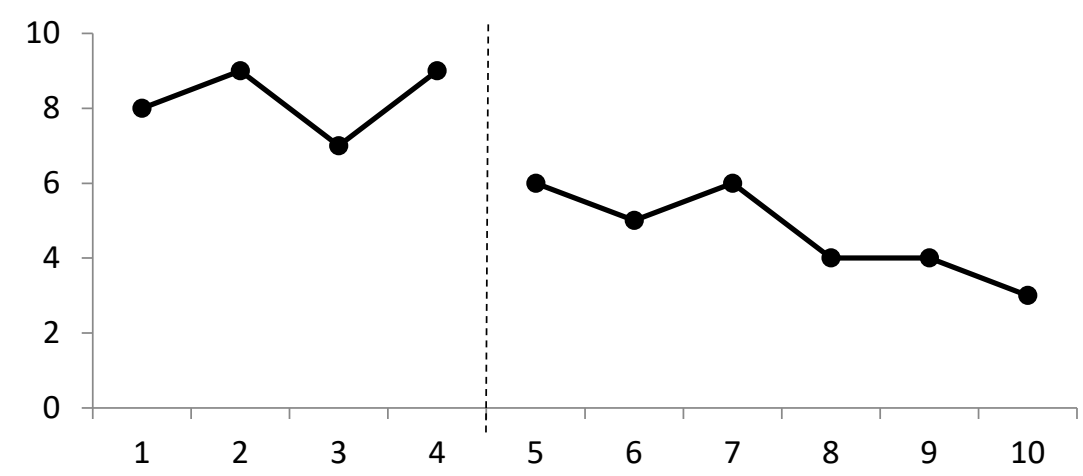

\section{Results}

The results of this study indicate that a visual activity schedule as well as an independent work system has a positive influence for this particular student with ASD within a resource classroom. The intervention presented for this assessment produced a decrease in off-task behavior as well as a decrease in adult prompting. The decreases in the dependent variables occurred when the intervention was introduced throughout a two week intervention phase. The PECS and independent work system gave the student, a better understanding of the daily schedule. The student also had a better understanding of what tasks to complete during his independent work time. These structured systems provided the student with less anxiety and frustration and made transitioning from one activity to another easier. The student gained some much needed independence and in turn the visual supports implemented in this paper helped the student have a much more successful educational school day.

\section{Conclusion}

Students with ASD have a wide variety of behaviors that can affect their educational environment. Specifically, in this study, the student had difficulties with staying on task, communication skills, and being dependent on adults. Often times, a visual system will be used to create cues of what will happen next. A visual system, PECS, was used during the study. The PECS system is implemented to help students with ASD communication, scheduling, or 
instructions. It was introduced in order to help the student gain independence, communicate via pictures, and complete tasks both desirable and undesirable with limited off task behaviors.

It was found that with the PECS system Derek was able to complete tasks with less prompting and less off task behaviors. In this case, the PECS system was a success. The student did gain independence by using a "check-in, check-out" process. This process required the student to "check-in" with his teacher when he was beginning an assignment and to "check-out" when his assignment was complete. He was able to communicate with the use of pictures. Once the assignment was complete, he was able to communicate which assignment he would begin in is "check-in, check-out” process. He also had smoother transitions and a decrease in off-task behaviors. This was due to the student knowing what was to come next through the PECS system.

This study showed the positive, educational impact visual supports could have on a student with ASD. The PECS system decreased prompting and off-task behaviors. It can also provide a student with less anxiety, better communication, increase task completion, and more independence. The PECS system was a success and has been proven to impact the student's educational learning in a positive way.

\section{References}

American Psychiatric Association (2000). Diagnostic and statistical manual of mental disorders (4 ${ }^{\text {th }}$ ed., text rev.). Washington, DC: American Psychiatric Association.

Bondy, A.S., \& Frost, L.A. (1994). The picture exchange communication system. Focus on Autistic Behavior, 9, 119.

Brock, S., Jimerson, S., \&Hansen, R. (2006). Identifying, Assessing, and Treating Autism at School. New York: Springer.

Fisher, N., \& Happe, F. (2005). A training study of theory of mind and executive function in children with autistic spectrum disorders. Journal of Autism and Developmental Disorders, 35, 757-771.

Happe. F., \& Frith. U. (2006). The weak coherence account: Detail focused cognitive style in autism spectrum disorders. Journal of Autism and Developmental Disorders, 36, 5-25.

Hodgdon, L.Q. (1995). Solving social-behavioral problems through the use of visually supported communication. In K.A. Quill (Ed.), Teaching children with autism: Strategies to enhance communication and socialization. New York: Delmar Publishers Inc

Hume, K., \& Reynolds, B., (2010). Implementing Work Systems across the School Day: Increasing Engagment in Students with Autism Spectrum Disorders. Preventing School Failure, 54(4), 228-237.

Hume, K. \& Odom, S. (2007). Effects of an individual work system on the independent functioning of students with autism. Journal of Autism and Developmental Disorders, 37, 1166-1180.

Hume, K., Plavnick, J., \& Odom, S. L. (2012). Promoting Task Accuracy and Independence in Students with Autism Across Educational Setting Through the

Use of Individual Work Systems. Journal of Autism and Developmental Disorders, 42, 2084-2099.

Iovannone, R., Dunlap, G., Huber, H., \& Kincaid, D. (2003). Effective educational practices for students with autism spectrum disorders. Focus on Autism and Other Deveopmental Disablities, 18, 150-165.

Koegel, R., \& Koegel, L. (1995). Teaching children with autism: Strategies for initiating positive interactions and improving learning opportunities. Baltimore: Paul H. Brookes.

Kluth, P., \& Darmody-Lantham, J., (2003). Beyond sight words: Literacy opportunities for students with autism. Reading Teacher, 56(6), 532-535.

Mesibov, G., Shea, V., \& Schopler, E. (2005). The TEACCH approach to autism spectrum disorders. New York: Plenum.

National Information Center for Children and Youth With Disabilities. (2004). Autism and pervasive developmental disorder: Fact sheet 1 (FSI). (Retrieved January 2, 2006, from http://www.nichcy.org.

National Research Council (2001). Educating Children with Autism. Committee on Educational Interventions for Children with Autism. Catherine Lord and James P. McGee, eds. Divisoin of Behavioral and Social Sciences and Education. Washington, DC: National Academy Press.

Quill, K. A. (2000). Do-watch-listen-say: Social and communication intervention for children with autism. Baltimore: Paul H. Brookes.

Rao, S., \& Gagie, B. (2006) Learning Through Seeing and Doing: Visual Supports for Children With Autism. TEACHING Exceptional Children, 38(6), 26-33. 
